\title{
Risk of Developing Postoperative Deficits Based on Tumor Location after Surgical Resection of an Intracranial Meningioma
}

\author{
Jeff S. Ehresman ${ }^{1}$ Tomas Garzon-Muvdi ${ }^{1}$ Davis Rogers ${ }^{1} \quad$ Michael Lim ${ }^{1}$ Gary L. Gallia ${ }^{1}$ \\ Jon Weingart ${ }^{1}$ Henry Brem ${ }^{1}$ Chetan Bettegowda ${ }^{1}$ Kaisorn L. Chaichana ${ }^{2}$ \\ 1 Department of Neurosurgery, Johns Hopkins University School of \\ Medicine, Johns Hopkins University, Baltimore, Maryland, United States \\ ${ }^{2}$ Department of Neurosurgery, Mayo Clinic Florida, Jacksonville, \\ Florida, United States \\ Address for correspondence Kaisorn L. Chaichana, MD, Department \\ of Neurosurgery, Mayo Clinic Florida, 4500 San Pablo Road, \\ Jacksonville, FL 32224, United States \\ (e-mail: kaisorn.chaichana@mayo.edu).
}

J Neurol Surg B 2019;80:59-66.

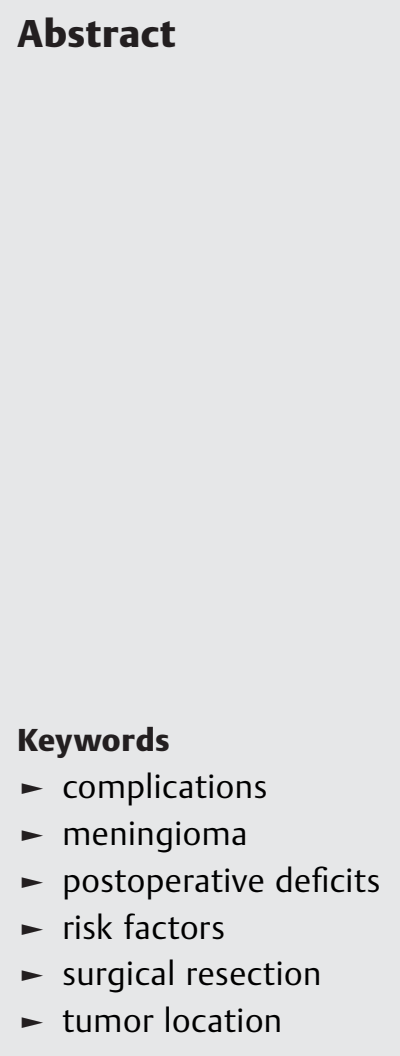

Object Meningiomas occur in various intracranial locations. Each location is associated with a unique set of surgical nuances and risk profiles. The incidence and risk factors that predispose patients to certain deficits based on tumor locations are unclear. This study aimed to determine which preoperative factors increase the risk of patients having new deficits after surgery based on tumor location for patients undergoing intracranial meningioma surgery.

Methods Adult patients who underwent primary, nonbiopsy resection of a meningioma at a tertiary care institution between 2007 and 2015 were retrospectively reviewed. Stepwise multivariate logistic regression analyses were used to identify associations with postoperative deficits based on tumor location.

Results Postoperatively, from the 761 included patients, there were 39 motor deficits (5.1\%), 23 vision deficits (3.0\%), 19 language deficits (2.5\%), 27 seizures (3.5\%), and 26 cognitive deficits (3.4\%). The factors independently associated with any postoperative deficits were preoperative radiation (hazard ratio [HR] [95\% confidence interval, $\mathrm{Cl}$ ] 3.000 [1.346-6.338], $p=0.008)$, cerebellopontine angle tumors ( $\mathrm{HR}[95 \% \mathrm{Cl}] 2.126$ [1.094-3.947], $p=0.03)$, Simpson grade 4 resections $(\mathrm{HR}[95 \% \mathrm{Cl}] 2.000$ [1.2713.127], $p=0.003)$, preoperative motor deficits (HR [95\% Cl] 1.738 [1.005-2.923], $p=0.048)$, preoperative cognitive deficits (HR [95\% Cl] 2.033 [1.144-3.504], $p=0.02$ ), and perioperative pulmonary embolisms (HR [95\% Cl] 11.741 [2.80359.314], $p=0.0009$ ).

Conclusion Consideration of the factors associated with postoperative deficits in this study may help guide treatment strategies for patients with meningiomas.

\section{Introduction}

\section{Background}

Surgical resection has long been the preferred treatment of meningiomas when treatment is pursued. This is usually the case for those tumors that are symptomatic, growing, or causing mass effect. ${ }^{1}$ These tumors are often erroneously considered easier to remove than other intracranial tumors because most have the perception of meningiomas in convexity locations. ${ }^{2}$ However, these surgeries, even those along the convexity, can still lead to complications and deficits. ${ }^{3}$ received

January 29, 2018

accepted after revision

June 6, 2018

published online

July 17, 2018
(C) 2019 Georg Thieme Verlag KG Stuttgart · New York
DOI https://doi.org/ 10.1055/s-0038-1667066. ISSN 2193-6331. 
Previous studies that have evaluated postoperative complications and deficits following meningioma surgery have only focused on a single location or a type of surgical complication. ${ }^{4-20}$ It therefore remains unclear how meningiomas in different locations differ in terms of postoperative complications and the factors that predispose to these complications. This is especially important as the incidence of meningiomas is rising as a result of widespread availability of neuroimaging. ${ }^{21}$

\section{Objectives}

The goals of this study were to: (1) determine how postoperative deficits vary with tumor location, and (2) determine the factors that are independently associated with higher rates of different postoperative deficits. An understanding of these objectives could allow for better guidance in providing informed consent to patients and their families, as well as developing techniques aimed at decreasing deficits during the surgical resection of meningiomas.

\section{Methods}

\section{Participants}

Institutional Review Board approval (72892) was obtained prior to the start of this study and all included patients gave their consent. All adult patients who underwent surgical resection of an intracranial meningioma at a single, tertiary care institution between 2007 and 2015 were recorded and reviewed.

\section{Recorded Variables}

Of the 852 patients who underwent surgery during the reviewed period, 90 were excluded. The exclusion criteria included those with multiple meningiomas, neurofibromatosis type 2 , radiation-induced meningiomas, or patients with tumors in locations not analyzed in this study. The locations analyzed were convexity, anterior skull base, parasagittal/ parafalcine, sphenoid wing, tentorial, cerebellopontine angle (CPA), and foramen magnum. Patients with meningiomas who did not undergo surgical resection or underwent needle biopsy were also excluded. This was done to create as uniform a population as possible to evaluate postoperative deficits for the most common meningioma locations. The clinical, operative, and hospital records of the remaining 761 patients were retrospectively reviewed. Recorded information included patient demographics, comorbidities, presenting symptoms, magnetic resonance imaging (MRI) findings, tumor pathology/ grade, and use of adjuvant therapy. Tumor pathology and grade were determined by a senior neuropathologist in all cases according to the 2007 World Health Organization (WHO) grading system. ${ }^{22}$ Patients were assigned a preoperative Karnofsky Performance Scale (KPS) by the chart reviewer based on preoperative symptoms. A motor deficit was defined as any decrease in strength. Vision deficits were divided into diplopia and visual field deficits. Patients with visual field deficits underwent Humphrey visual field testing by an ophthalmologist. A cognitive deficit was recorded if the patient had any signs of decreased mental ability, and possible deficits were formally evaluated by speech and language pathology. ${ }^{23}$ Postoperative seizures included any seizure within 48 hours after surgery.

All MRI images were obtained and reviewed. The characteristics that were recorded included the lesions' volume and longest dimension. Tumor appearance included location, sinus invasion, midline shift, and the presence of edema or cysts. Tumor locations were both analyzed separately and grouped with others based on similar characteristics. ${ }^{24}$ Extent of resection was recorded as Simpson grade 1 through 4 by postoperative neuroimaging obtained within 48 hours of surgery and operative reports. ${ }^{25}$ The primary outcome evaluated for each patient was the presence of new or worsened postoperative deficits that were persistent (present at last follow-up). The following postoperative outcomes were assessed: new motor deficits, new vision deficits, seizures, and new cognitive deficits.

\section{Statistical Methods}

Stepwise multivariate logistic regression analyses were performed to identify factors independently associated with different postoperative deficits. In these analyses, univariate analysis was first performed to identify potential associations between radiographic, preoperative, operative, perioperative, and pathologic variables with postoperative deficits. All variables associated with postoperative deficits in univariate analysis $(p<0.10)$ were then analyzed in a stepwise multivariate logistic regression model. ${ }^{26}$ Values with $p<0.05$ in these analyses were considered statistically significant. Intergroup analyses were also performed using Student's $t$-test and Fisher's exact test for continuous and categorical data, respectively. JMP Pro 12 (SAS, Cary, North Carolina, United States) was used unless otherwise specified. Authors adhered to the Strengthening the Reporting of Observational Studies in Epidemiology guidelines in this study.

\section{Results}

Preoperative Patient Characteristics, Outcomes, and Differences between Tumor Locations

The preoperative characteristics and outcomes of the 761 patients who underwent surgical resection of an intracranial meningioma are summarized in - Table 1. The average age ( \pm standard deviation) was $55.7( \pm 12.8)$ years, and $202(26.5 \%)$ were male. The median (interquartile range) KPS score was 80 (80-90). Note that 682 of the 761 meningiomas were WHO grade 1 (91.5\%), 57 (7.7\%) were WHO grade 2 , and $6(0.8 \%)$ were WHO grade 3. After performing intergroup comparisons between meningiomas in different locations, white patients had a lower incidence of anterior skull base meningiomas compared with other locations $(p=0.05)$. African American patients had a higher incidence of anterior skull base tumors compared with other locations $(p=0.01)$. - Fig. 1 illustrates the total percentage of postoperative deficits in each intracranial location. Convexity tumor resections had the lowest incidence of postoperative motor deficits $(p=0.006)$. Tumors located in the CPA were associated with the highest rate of postoperative diplopia $(p=0.0002)$. Tumors located in the 
Table 1 Demographic table

\begin{tabular}{|c|c|c|c|c|c|c|c|c|}
\hline & Convexity & $\begin{array}{l}\text { Anterior } \\
\text { skull-base }\end{array}$ & $\begin{array}{l}\text { Parasagittal }+ \\
\text { Parafalcine }\end{array}$ & Tentorial & $\mathrm{CPA}$ & $\begin{array}{l}\text { Foramen } \\
\text { magnum }\end{array}$ & $\begin{array}{l}\text { Sphenoid } \\
\text { wing }\end{array}$ & Total \\
\hline & $\mathrm{n}=\mathbf{2 0 8}$ & $\mathrm{n}=97$ & $n=204$ & $n=43$ & $\mathrm{n}=71$ & $n=12$ & $n=126$ & $N=761$ \\
\hline Age (avg) & 55.7 & 56.5 & 55.7 & 55.7 & 54.3 & 52.5 & 56.0 & 55.7 \\
\hline Male & $63(30.3 \%)$ & $27(27.8 \%)$ & $63(30.9 \%)$ & $\begin{array}{l}5 \\
(11.6 \%)\end{array}$ & $13(18.1 \%)$ & $\begin{array}{l}3 \\
(23.1 \%)\end{array}$ & $28(22.0 \%)$ & $202(26.5 \%)$ \\
\hline KPS $>70$ & $176(84.6 \%)$ & $81(83.5 \%)$ & $168(82.3 \%)$ & $35(81.4 \%)$ & 59 (81.9\%) & $10(76.9 \%)$ & $98(77.2 \%)$ & $625(82.0 \%)$ \\
\hline White & $154(74.4 \%)$ & $59(60.8 \%)$ & $156(76.5 \%)$ & $31(72.1 \%)$ & $52(72.2 \%)$ & $\begin{array}{l}9 \\
(69.2 \%)\end{array}$ & $86(67.7 \%)$ & $545(71.6 \%)$ \\
\hline $\begin{array}{l}\text { African } \\
\text { American }\end{array}$ & $27(13.0 \%)$ & $26(26.8 \%)$ & $27(13.2 \%)$ & $\begin{array}{l}7 \\
(16.3 \%)\end{array}$ & $\begin{array}{l}8 \\
(11.1 \%)\end{array}$ & $\begin{array}{l}2 \\
(15.4 \%)\end{array}$ & $27(21.2 \%)$ & $124(16.3 \%)$ \\
\hline Hispanic & $1(0.5 \%)$ & $1(1.0 \%)$ & $3(1.5 \%)$ & 0 & $1(1.4 \%)$ & 0 & $2(1.6 \%)$ & $8(1.1 \%)$ \\
\hline Asian & $5(2.4 \%)$ & $4(4.1 \%)$ & $7(3.4 \%)$ & $2(4.7 \%)$ & $3(4.2 \%)$ & 0 & $3(2.4 \%)$ & $24(3.2 \%)$ \\
\hline \multicolumn{9}{|c|}{ Postop complications } \\
\hline Motor deficit & $3(1.4 \%)$ & $2(2.1 \%)$ & $12(5.9 \%)$ & $5(11.6 \%)$ & $8(11.1 \%)$ & $2(15.4 \%)$ & $7(5.5 \%)$ & 39 (5.1\%) \\
\hline Diplopia & $1(0.5 \%)$ & $2(2.1 \%)$ & 0 & $1(0.1 \%)$ & 6 (8.5\%) & 0 & $2(1.6 \%)$ & 10 (1.3\%) \\
\hline $\begin{array}{l}\text { Visual field } \\
\text { deficit }\end{array}$ & $1(0.5 \%)$ & 7 (7.2\%) & $1(0.5 \%)$ & 0 & 0 & 0 & $3(2.4 \%)$ & $10(1.3 \%)$ \\
\hline $\begin{array}{l}\text { Language } \\
\text { deficit }\end{array}$ & $4(1.9 \%)$ & $1(1.0 \%)$ & 7 (3.4\%) & 0 & $2(2.8 \%)$ & $1(7.7 \%)$ & $4(3.2 \%)$ & 19 (2.5\%) \\
\hline $\begin{array}{l}\text { Postop } \\
\text { seizure }\end{array}$ & $9(4.3 \%)$ & $3(3.1 \%)$ & $5(2.5 \%)$ & 2 (4.7\%) & 1 (1.4\%) & 0 & 7 (5.5\%) & 27 (3.5\%) \\
\hline $\begin{array}{l}\text { Cognitive } \\
\text { deficit }\end{array}$ & $4(1.9 \%)$ & 7 (7.2\%) & $4(2.0 \%)$ & $1(2.3 \%)$ & $3(4.2 \%)$ & 0 & 7 (5.5\%) & $26(3.4 \%)$ \\
\hline \multicolumn{9}{|l|}{ WHO grade } \\
\hline 1 & $179(87.3 \%)$ & $90(94.7 \%)$ & 176 (88.9\%) & 40 (93.0\%) & 69 (97.2\%) & 11 (91.7\%) & $119(96.7 \%)$ & $682(91.5 \%)$ \\
\hline II & 21 (10.2\%) & $\begin{array}{l}5 \\
(5.3 \%)\end{array}$ & 21 (10.6\%) & $\begin{array}{l}3 \\
(7.0 \%)\end{array}$ & $\begin{array}{l}2 \\
(2.8 \%)\end{array}$ & $\begin{array}{l}1 \\
(8.3 \%)\end{array}$ & $\begin{array}{l}4 \\
(3.3 \%)\end{array}$ & $\begin{array}{l}57 \\
(7.7 \%)\end{array}$ \\
\hline III & $5(2.4 \%)$ & 0 & $1(0.5 \%)$ & 0 & 0 & 0 & 0 & $6(0.8 \%)$ \\
\hline \multicolumn{9}{|c|}{ Simpson grade } \\
\hline 1 & 111 (53.4\%) & $\begin{array}{l}3 \\
(3.1 \%)\end{array}$ & 41 (20.1\%) & $\begin{array}{l}4 \\
(9.3 \%)\end{array}$ & $\begin{array}{l}4 \\
(5.6 \%)\end{array}$ & $\begin{array}{l}2 \\
(15.4 \%)\end{array}$ & $13(10.2 \%)$ & $178(23.4 \%)$ \\
\hline II & 47 (22.6\%) & 38 (39.2\%) & $88(43.1 \%)$ & $14(32.6 \%)$ & 28 (38.9\%) & $\begin{array}{l}4 \\
(30.8 \%) \\
\end{array}$ & 37 (29.1\%) & $256(33.6 \%)$ \\
\hline III & 32 (15.4\%) & $16(16.5 \%)$ & 25 (12.3\%) & $\begin{array}{l}7 \\
(16.3 \%) \\
\end{array}$ & $\begin{array}{l}7 \\
(9.7 \%) \\
\end{array}$ & $\begin{array}{l}1 \\
(7.7 \%)\end{array}$ & $30(23.6 \%)$ & 118 (15.5\%) \\
\hline IV & $\begin{array}{l}18 \\
(8.7 \%)\end{array}$ & $40(41.2 \%)$ & 50 (24.5\%) & $18(41.9 \%)$ & $33(45.8 \%)$ & $\begin{array}{l}6 \\
(46.2 \%)\end{array}$ & 47 (37.0\%) & $210(26.6 \%)$ \\
\hline \multicolumn{9}{|l|}{ Outcomes } \\
\hline Recurring & $24(11.7 \%)$ & $10(10.3 \%)$ & $35(17.2 \%)$ & $\begin{array}{l}3 \\
(7.0 \%)\end{array}$ & $\begin{array}{l}5 \\
(6.9 \%)\end{array}$ & $\begin{array}{l}2 \\
(15.4 \%)\end{array}$ & 25 (19.8\%) & $102(13.5 \%)$ \\
\hline Mortality & $\begin{array}{l}9 \\
(4.3 \%)\end{array}$ & $\begin{array}{l}3 \\
(3.1 \%)\end{array}$ & $\begin{array}{l}12 \\
(5.9 \%)\end{array}$ & $\begin{array}{l}3 \\
(7.0 \%)\end{array}$ & 0 & $\begin{array}{l}2 \\
(15.4 \%)\end{array}$ & $\begin{array}{l}12 \\
(9.4 \%)\end{array}$ & $\begin{array}{l}41 \\
(5.4 \%)\end{array}$ \\
\hline
\end{tabular}

Abbreviations: CPA, cerebellopontine angle; KPS, Karnofsky Performance Scale; WHO, World Health Organization.

Note: Bolded values are statistically different from other tumor locations.

anterior skull base were associated with the highest rate of decreased visual fields after surgery $(p=0.0003)$. WHO grade 1 tumors were less likely to be located in the convexity or parasagittal/parafalcine than other locations $(p=0.009$ and $p=0.05$, respectively). Simpson grade 1 resections were performed significantly more with convexity and parasagittal/ parafalcine tumors ( $p \leq 0.0001$ and $p=0.02$, respectively), and significantly less with anterior skull base tumors $(p=0.004)$. Simpson grade 2 resections were performed sig- nificantly more with parasagittal/parafalcine tumors $(p=0.02)$ and significantly less with convexity tumors $(p=0.002)$. Simpson grade 3 resections were performed to a significantly higher degree with sphenoid wing meningiomas $(p=0.01)$. Simpson grade 4 resections were performed significantly more often with CPA meningiomas ( $p=0.02$ ), and significantly less in convexity and parasagittal/parafalcine tumors ( $p \leq 0.0001$ and $p=0.04$, respectively). Parasagittal/parafalcine and sphenoid wing meningiomas were found to recur at a higher rate than 
Intracranial location vs. Postoperative deficits

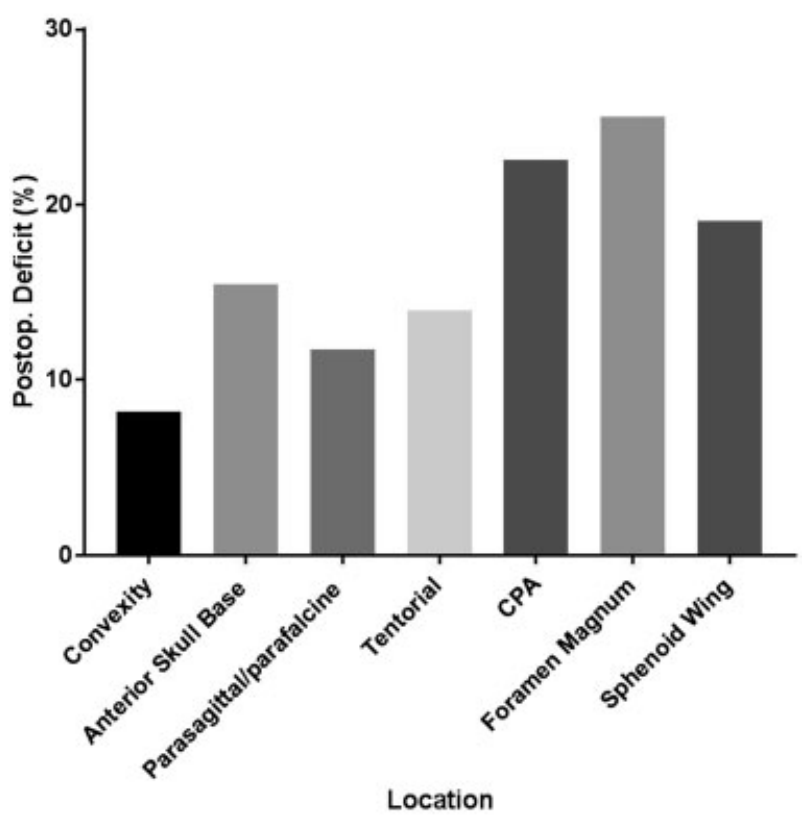

Fig. 1 Mean number of all postoperative deficits according to intracranial location.

other meningiomas ( $p=0.02$ and $p=0.01$, respectively). We found no other pre-, peri-, or postoperative differences between the different tumor locations analyzed in the study.

\section{Factors Associated with Any Postoperative Deficits}

The factors associated with any postoperative deficits after surgical resections are summarized in -Table 2. In univariate analysis, the factors associated with any postoperative deficit were sphenoid wing tumors, CPA tumors, Simpson grade 1 and 4 resections, age, prior anticoagulation, coronary artery disease, previous coronary artery bypass graft (CABG)/stents, KPS $<70$, preoperative motor and cognitive deficits, previously recurring meningioma, postoperative pulmonary embolism, intraoperative ventricle entry, tumor volume, preoperative radiation, and postoperative prophylactic radiation. In stepwise multivariate analysis, the factors independently associated with any postoperative deficits were preoperative radiation (hazard ratio [HR] [95\% confidence interval, $\mathrm{CI}] 3.000$ [1.346-6.338], $p=0.008$ ), CPA tumors (HR [95\% CI] 2.126 [1.094-3.947], $p=0.03$ ), Simpson grade 4 resections (HR [95\% CI] 2.000 [1.271-3.127], $p=0.003$ ), preoperative motor deficits (HR [95\% CI] 1.738 [1.005-2.923], $p=0.048$ ), preoperative cognitive deficits (HR [95\% CI] 2.033 [1.144-3.504], $p=0.02$ ), and postoperative pulmonary embolisms (HR [95\% CI] 11.741 [2.803-59.314], $p=0.0009$ ).

Factors Associated with Postoperative Motor Deficits The factors associated with higher risk for postoperative motor deficits are summarized in -Table 3. In univariate analysis, the factors associated with postoperative motor deficits were tentorial tumors, CPA tumors, Simpson grade 1 and 4 resections, and postoperative pulmonary embolisms. In stepwise multivariate analysis, the factors independently
Table 2 Independent factors associated with any deficits after surgical resection for intracranial meningiomas

\begin{tabular}{|c|c|c|}
\hline \multicolumn{3}{|c|}{$\begin{array}{l}\text { Multivariate stepwise logistic regression for any new } \\
\text { deficits }\end{array}$} \\
\hline Risk factors & $p$-Value & OR [95\% Cl] \\
\hline Preoperative radiation & 0.008 & $3.000[1.346-6.338]$ \\
\hline $\begin{array}{l}\text { Cerebellopontine } \\
\text { angle location }\end{array}$ & 0.027 & $2.126[1.094-3.947]$ \\
\hline $\begin{array}{l}\text { Simpson grade } \\
4 \text { resection }\end{array}$ & 0.003 & $2.000[1.271-3.127]$ \\
\hline Preop motor deficit & 0.048 & $1.738[1.005-2.923]$ \\
\hline Preop cognitive deficit & 0.017 & $2.033[1.144-3.504]$ \\
\hline $\begin{array}{l}\text { Periop pulmonary } \\
\text { embolism }\end{array}$ & 0.0009 & $11.741[2.803-59.314$ \\
\hline
\end{tabular}

Abbreviations: $\mathrm{Cl}$, confidence interval; OR, odds ratio.

Table 3 Independent factors associated with motor deficits after surgical resection for intracranial meningiomas

\begin{tabular}{|c|c|c|}
\hline \multicolumn{3}{|c|}{$\begin{array}{l}\text { Multivariate stepwise logistic regression for new motor } \\
\text { deficit }\end{array}$} \\
\hline Risk factors & $p$-Value & OR $[95 \% \mathrm{Cl}]$ \\
\hline $\begin{array}{l}\text { Periop pulmonary } \\
\text { embolism }\end{array}$ & 0.0005 & $17.255[3.949-71.336]$ \\
\hline $\begin{array}{l}\text { Simpson grade } \\
4 \text { resection }\end{array}$ & 0.001 & $3.011[1.545-5.900]$ \\
\hline
\end{tabular}

Abbreviations: $\mathrm{Cl}$, confidence interval; OR, odds ratio.

associated with postoperative motor deficits were perioperative pulmonary embolisms (HR [ $\left[\begin{array}{lll}95 \% & \mathrm{CI}\end{array}\right] 17.255$ [3.949-71.336], $p=0.0005)$ and Simpson grade 4 resections (HR [95\% CI] 3.011 [1.545-5.900], $p=0.001$ ).

\section{Factors Associated with Postoperative Diplopia or Visual Field Deficits}

The factors associated with higher risk for postoperative diplopia and visual deficits are summarized in - Tables 4 and $\mathbf{5}$, respectively. In univariate analysis, the only factor associated with postoperative diplopia was the CPA location (HR [95\% CI] 10.538 [3.213-34.592], $p=0.0003$ ). The factor significantly associated with decreased visual fields postoperatively was the anterior skull-base location (HR [95\% CI] 10.267 [3.21135.331], $p=0.0002$ ).

Table 4 Independent factors associated with diplopia after surgical resection for intracranial meningioma

\begin{tabular}{|l|l|l|}
\hline \multicolumn{3}{|l|}{ Multivariate stepwise logistic regression for new diplopia } \\
\hline Risk factors & $p$-Value & OR $[95 \% \mathrm{CI}]$ \\
\hline $\begin{array}{l}\text { Cerebellopontine } \\
\text { angle location }\end{array}$ & 0.0003 & $10.538[3.213-34.592]$ \\
\hline
\end{tabular}

Abbreviations: $\mathrm{Cl}$, confidence interval; OR, odds ratio. 
Table 5 Independent factors associated with visual field deficits after surgical resection for intracranial meningioma

\begin{tabular}{|c|c|c|}
\hline \multicolumn{3}{|c|}{$\begin{array}{l}\text { Multivariate stepwise logistic regression for new visual } \\
\text { field deficit }\end{array}$} \\
\hline Risk factors & $p$-Value & OR $[95 \% \mathrm{Cl}]$ \\
\hline $\begin{array}{l}\text { Anterior skull } \\
\text { base location }\end{array}$ & 0.0002 & $10.267[3.211-35.331]$ \\
\hline
\end{tabular}

Table 6 Independent factors associated with seizures after surgical resection for intracranial meningioma

\begin{tabular}{|l|l|l|}
\hline \multicolumn{3}{|l|}{$\begin{array}{l}\text { Multivariate stepwise logistic regression for } \\
\text { postoperative seizure }\end{array}$} \\
\hline Risk factor & $p$-Value & OR [95\% Cl] \\
\hline $\begin{array}{l}\text { Extent of } \\
\text { midline shift }\end{array}$ & 0.0083 & $1.143[1.038-1.248]$ \\
\hline $\begin{array}{l}\text { Recurrent } \\
\text { meningioma }\end{array}$ & 0.0056 & $4.146[1.544-10.673]$ \\
\hline $\begin{array}{l}\text { Preop motor } \\
\text { deficits }\end{array}$ & 0.0049 & $3.6931 .509-8.817]$ \\
\hline Preop seizures & 0.0348 & $2.975[1.086-7.592]$ \\
\hline $\begin{array}{l}\text { Periop pulmonary } \\
\text { embolism }\end{array}$ & $<0.0001$ & $45.781[10.006-222.398]$ \\
\hline
\end{tabular}

\section{Factors Associated with Postoperative Seizures}

The factors associated with higher risk for postoperative seizures are summarized in $\mathbf{- T a b l e ~} \mathbf{6}$. In univariate analysis, the factors associated with postoperative seizures were previously recurring meningiomas, coronary artery disease, diabetes mellitus, KPS $<70$, intraoperative ventricle entry, preoperative motor deficits and seizures, pulmonary embolism, tumor volume, extent of midline shift, and preoperative radiation. In stepwise multivariate analysis, the factors independently associated with seizures were increasing midline shift (HR [95\% CI] 1.143 [1.038-1.248], $p=0.008$ ), previously recurring meningiomas (HR $[95 \% \mathrm{CI}] 4.146$ [1.544-10.673], $p=0.006)$, preoperative motor deficits (HR [95\% CI] 3.693 [1.509-8.817], $p=0.005$ ), preoperative seizures (HR [95\% CI] 2.975 [1.086-7.592], $p=0.03$ ), and perioperative pulmonary embolism ( $\mathrm{HR}$ [95\% CI] 45.781 [10.006-222.398], $p<0.0001)$.

\section{Factors Associated with Postoperative Cognitive Deficits}

The factors associated with higher risk for postoperative cognitive deficits are summarized in -Table 7. In univariate analysis, the factors associated with postoperative cognitive deficits were male, age, coronary artery disease, previous CABG/stents, hypertension, prior anticoagulation, KPS score $<70$, and preoperative cognitive deficits. In stepwise multivariate analysis, the factors independently associated with cognitive deficits were older age (HR [95\% CI] 1.038 [1.0021.075], $p=0.04$ ), CABG/stents (HR [95\% CI] 1.038 [1.0021.075], $p=0.04$ ), and preoperative KPS $<70$ (HR [95\% CI] 2.805 [1.184-6.417], $p=0.02$ ).
Table 7 Independent factors associated with cognitive deficits after surgical resection for intracranial meningioma

\begin{tabular}{|l|l|l|}
\hline \multicolumn{3}{|l|}{$\begin{array}{l}\text { Multivariate stepwise logistic regression for new } \\
\text { cognitive deficits }\end{array}$} \\
\hline Risk factor & $p$-Value & OR [95\% Cl] \\
\hline Older age & 0.0378 & $1.038[1.002-1.075]$ \\
\hline Previous CABG/stents & 0.0014 & $6.274[2.137-17.070]$ \\
\hline Preop KPS $<70$ & 0.0201 & $2.805[1.184-6.417]$ \\
\hline
\end{tabular}

Abbreviations: $\mathrm{CABG}$, coronary artery bypass graft; $\mathrm{Cl}$, confidence interval; KPS, Karnofsky Performance Scale; OR, odds ratio.

\section{Discussion}

\section{Key Results}

In this study, we observed 134 postoperative deficits in 761 patients. Independent risk factors for postoperative deficits were preoperative radiation, tumors outside of the convexity, CPA tumors, subtotal resections, coronary artery disease, and preoperative motor or cognitive deficits. Independent risk factors for postoperative motor deficits were pulmonary embolisms, nonconvexity tumors, subtotal resections, and intraoperative ventricle entry. Independent risk factors for postoperative vision deficits were tumors outside of the convexity, parasagittal, or parafalcine areas. Independent risk factors for seizures within 48 hours of surgery were extent of midline shift, previously recurring meningioma, preoperative motor deficits, preoperative seizures, and pulmonary embolisms. Independent risk factors for postoperative cognitive deficits were age, previous CABG/stents, and KPS scores below 70 .

\section{Prior Studies on Postoperative Deficits after Meningioma Resection}

Surgical resection of meningiomas are widely performed and are often associated with good outcomes. ${ }^{27}$ As a result, many surgeons and patients erroneously perceive that these tumors are straightforward and without complications. ${ }^{27}$ However, the surgical difficulty and risk profiles for meningiomas in different locations is distinct. A comparison between meningiomas in different locations as it relates to postoperative complications has yet to be done in a large modern patient population. Li et al analyzed 199 patients with petroclival meningiomas for risk factors associated with poor postoperative KPS score, hemiparesis, and cranial nerve deficits, and found that these included surgery history, age, tumor size, tumor consistency, vital artery encasement, peritumoral edema, and absence of tumor-brainstem interface. ${ }^{10}$ The largest study on postoperative outcomes was performed by Wirsching et al looking specifically at postoperative epilepsy. ${ }^{20}$ They found that independent risk factors of seizures include preoperative epilepsy, surgical complications, hydrocephalus, recurrent surgery, symptomatic intracranial hemorrhage, age, and tumor progression. ${ }^{20}$ Therefore, the factors associated with postoperative deficits as it relates to tumor location for patients undergoing intracranial meningioma surgery would 
help inform surgeons and their patients about the potential risks of deficits, as well as potentially develop ways to minimize these risks.

\section{Factors Independently Associated with Postoperative Deficits}

Any Postoperative Deficits

This study observed 134 postoperative deficits (18\%) after meningioma resections in 761 patients. CPA tumors had the largest incidence of postoperative deficits (27.8\%). The factors independently associated with any postoperative deficits were preoperative radiation, CPA tumors, Simpson grade 4 resections, preoperative motor and cognitive deficits, and perioperative pulmonary embolisms. Preoperative radiation is more often performed on meningiomas that appear most aggressive, so it is likely that this factor led to more difficult surgeries with more postoperative deficits. ${ }^{28}$ Subtotal resections may lead to excessive swelling of residual tumor, leading to the postoperative deficits we observed in these cases. Also, these meningiomas were likely located in complex areas, making them more difficult to resect while also carrying greater chances of causing neurological dysfunctions. While a subtotal resection is often chosen due to the high risk of a gross total resection during a case, it is important to note that there may be also be some innate postoperative risk of leaving tumor behind. Tumors near the CPA often involve complex surgical fields, leading to more subtotal resections. It has been demonstrated that a lower preoperative functional status can increase risk for worse functional outcomes after meningioma resection. ${ }^{25}$ This supports our finding that preoperative motor and cognitive deficits can lead to more postoperative deficits. Lastly, pulmonary embolisms have been found to lead to potentially devastating surgical complications, even involving death in the worst cases. ${ }^{29,30}$

\section{Postoperative Motor Deficits}

In this study, 39 patients (5.1\%) had postoperative motor deficits after surgery. Tumors removed from the tentorium and the foramen magnum had the highest rates of motor deficits (11.6\% and $15.4 \%$, respectively). The factors independently associated with postoperative motor deficits were incomplete resection (Simpson grade 4) and perioperative pulmonary embolisms. Oyama et al analyzed postoperative motor deficits in 16 cases with parasagittal/ parafalcine tumors and found these deficits to be caused by either an intracerebral hematoma or newly developed brain edema. ${ }^{14}$ Batra et al performed a similar study with CPA tumors and found tumor size and preoperative facial nerve paresis to have the highest associations with postoperative motor deficits. ${ }^{4}$ We did not find tumor size or edema to be associated with these deficits. In addition, the association between incomplete resections and motor deficits may be a result of intraoperative decision making caused by decreased intraoperative signals and/or difficulty in resecting tumor. Tumors that are incompletely resected may also predispose the brain to significant edema leading to neurological deficits. Lastly, perioperative pulmonary embolisms are known to cause a large range of deficits, one of which being motor function. 29,30

\section{Postoperative Vision Deficits}

In total, 22 patients (2.9\%) had postoperative vision deficits. Twelve patients (1.5\%) had diplopia, and 12 patients $(1.5 \%)$ had worsened visual fields (two patients had both vision deficits). Postoperative diplopia was significantly associated with CPA location, and decreased visual fields were significantly associated with anterior skull base location. Cosetti et al also found postoperative diplopia to be significantly associated with tumors in the CPA. ${ }^{31}$ They found this result to be due to acute vestibular deafferentation leading to skew deviation; however, this mechanism was not investigated in this study. ${ }^{31}$ Schick and Hassler also found visual field deficits to be associated with tumors in the anterior skull. ${ }^{16}$ One study analyzed 65 patients with medial sphenoid wing meningiomas and found that factors leading to postoperative vision deficits were preoperative visual decline, subtotal resection, and repeat surgery. ${ }^{7}$ Any compression to the optic chiasm or optic nerves is able to cause field deficits, so this association with tumors in the proximity was not surprising.

\section{Postoperative Seizures}

Our study observed that 27 patients (3.5\%) had seizures after surgical resections. The factors independently associated with postoperative seizures were extent of midline shift, revision resections, preoperative motor deficits, preoperative seizures, and perioperative pulmonary embolisms. Wirsching et al analyzed 779 patients and found that 104 (19.4\%) suffered from postoperative epileptic seizures. ${ }^{20}$ of these patients, they found risk factors to include preoperative seizures, major surgical complications, hydrocephalus, revision surgery, intracranial hemorrhage, younger age, and tumor progression. ${ }^{20}$ Zheng et al analyzed 97 patients and found that the only risk factor to postoperative seizures was the co-occurrence of new permanent neurological deficits. ${ }^{32}$ Our findings that increased midline shift leads to higher risk for seizures is in line with one study that found mass effect from meningiomas led to generalized seizures. ${ }^{33}$ Our study was also similar to that of Wirsching et al in finding that reresections and preoperative seizures were independently associated with postoperative seizures. ${ }^{20}$ Patients with preoperative seizures are at risk of postoperative seizures as has been seen with other tumors including metastatic brain tumors and malignant gliomas. ${ }^{34,35}$ In addition, the motor cortex is known to be susceptible to initiation of seizures; therefore, patients with preoperative motor deficits may be especially at risk as the tumor has likely already affected these regions. ${ }^{36}$ In addition, perioperative pulmonary embolisms were independently found to be associated with postoperative seizures. The presence of these thrombotic events can affect intracranial pressure, cerebral blood flow, and cerebral autoregulation, thus predisposing to seizures. ${ }^{29}$ Furthermore, pulmonary embolisms may actually be a consequence of postoperative deficits, due to increased hospital stays and decreased mobilization. 


\section{Postoperative Cognitive Deficits}

We found 26 patients (3.4\%) to have new cognitive deficits after meningioma resections. Comparing intracranial locations, removal of tumors from anterior skull base led to the highest proportion of cognitive deficits after surgery (7.2\%). The factors independently associated with postoperative cognitive decline were age and previous CABG/stents. Dijkstra et al analyzed 89 patients who underwent treatment for meningiomas and found that lower executive functioning was associated with a greater preoperative epilepsy burden. ${ }^{37}$ However, there were no presurgical assessments of cognitive function in this study. ${ }^{37}$ Krupp et al examined the outcomes for 91 patients after surgical resection of their meningiomas and found increasing age to be the most significant risk factor for postoperative neuropsychological problems, which was supported as an independent risk factor in our study. ${ }^{9}$ Although the pathophysiological mechanism for this link is unknown, studies have shown that patients undergoing CABG surgery are inclined to have postoperative deficits after their cardiac surgery. ${ }^{28,38}$ While a direct link cannot be made in our study, our results may give evidence that this post-CABG cognitive decline was exacerbated by meningioma resection.

\section{Strengths and Limitations}

We believe this study provides valuable information for patients and their neurosurgical care teams. This is the first study to analyze the risk factors for all postoperative deficits in the common meningioma tumor locations. We were able to use our relatively large patient sample size to determine what predisposing factors should be considered when aiming to minimize risk of these deficits. Other studies have largely focused on specific deficits or tumor locations, leading to small sample sizes with less generalizable results. ${ }^{5-20,28}$ Our study concludes that there are preoperative factors that can predispose patients to higher risks of postoperative deficits, allowing providers to consider these when planning for surgery and postoperative care.

While we believe this study provides the most relevant information concerning postoperative deficits from meningioma removal, the study is not without limitations. One limitation is that we limited our study to the most common meningioma locations. Our aim for this study was to be a comprehensive analysis of general groupings, while differentiating between olfactory groove and planum, for example, would likely require much higher multi-institutional studies to give clinically relevant conclusions. We also decided to combine locations that were close in proximity including planum and olfactory groove lesions, sagittal and parafalcine lesions, and medial/middle/lateral sphenoid wing lesions. We did this to increase the generalizability of our study; however, we understand that there are likely different risk factors between these locations that were not focused on in this study. Moreover, we also analyzed cognitive deficits based on neurological exam and patients and their families' perception of their recovery. Not all patients underwent neurocognitive testing, which would provide more objective information about postoperative cognitive function. Another limitation includes findings that we were unable to explain. For example, we did not have an explanation why African Americans were more likely to have meningiomas in anterior skull base compared with other locations. Lastly, our study includes the limitations present in a retrospective review, including inherent bias in patient or treatment selection. Therefore, prospective studies are necessary to confirm that knowledge of the risk factors we discovered can decrease postoperative patient deficits, with it ideally being done across multiple institutions with varying patient populations.

\section{Conclusion}

While surgical resection remains the gold standard for the treatment of a significant number of meningiomas, the risk for postoperative deficits is unclear. Based on tumor locations, we found that meningiomas in the convexity are much safer to resect in terms of postoperative deficits. The factors that were independently associated with different types of postoperative deficits were distinct. By accounting for these risk factors, surgeons may be able to better inform patients about the risk of deficits, as well as attempting to adjust their strategies to minimize the risk of postoperative neurological deficits.

\section{References}

1 Adegbite AB, Khan MI, Paine KW, Tan LK. The recurrence of intracranial meningiomas after surgical treatment. J Neurosurg 1983;58(01):51-56

2 Sanai N, Sughrue ME, Shangari G, Chung K, Berger MS, McDermott MW. Risk profile associated with convexity meningioma resection in the modern neurosurgical era. J Neurosurg 2010;112(05): 913-919

3 Alvernia JE, Sindou MP. Preoperative neuroimaging findings as a predictor of the surgical plane of cleavage: prospective study of 100 consecutive cases of intracranial meningioma. J Neurosurg 2004;100(03):422-430

4 Batra PS, Dutra JC, Wiet RJ. Auditory and facial nerve function following surgery for cerebellopontine angle meningiomas. Arch Otolaryngol Head Neck Surg 2002;128(04):369-374

5 Bekelis K, Bakhoum SF, Desai A, Mackenzie TA, Roberts DW. Outcome prediction in intracranial tumor surgery: the National Surgical Quality Improvement Program 2005-2010. J Neurooncol 2013;113(01):57-64

6 Bommakanti K, Somayajula S, Suvarna A, et al. Pre-operative and post-operative cognitive deficits in patients with supratentorial meningiomas. Clin Neurol Neurosurg 2016;143:150-158

7 Chaichana KL, Jackson C, Patel A, et al. Predictors of visual outcome following surgical resection of medial sphenoid wing meningiomas. J Neurol Surg B Skull Base 2012;73(05):321-326

8 Dickinson H, Carico C, Nuño M, Nosova K, Elramsisy A, Patil CG. The effect of weight in the outcomes of meningioma patients. Surg Neurol Int 2013;4:45

9 Krupp W, Klein C, Koschny R, Holland H, Seifert V, Meixensberger $\mathrm{J}$. Assessment of neuropsychological parameters and quality of life to evaluate outcome in patients with surgically treated supratentorial meningiomas. Neurosurgery 2009;64(01):40-47, discussion 47

10 Li D, Tang J, Ren C, Wu Z, Zhang LW, Zhang JT. Surgical management of medium and large petroclival meningiomas: a single institution's experience of 199 cases with long-term follow-up. Acta Neurochir (Wien) 2016;158(03):409-425, discussion 425 
11 Liouta E, Koutsarnakis C, Liakos F, Stranjalis G. Effects of intracranial meningioma location, size, and surgery on neurocognitive functions: a 3-year prospective study. J Neurosurg 2016;124(06): 1578-1584

12 Little KM, Friedman AH, Sampson JH, Wanibuchi M, Fukushima T. Surgical management of petroclival meningiomas: defining resection goals based on risk of neurological morbidity and tumor recurrence rates in 137 patients. Neurosurgery 2005;56(03): 546-559, discussion 546-559

13 Nanda A, Bir SC, Maiti TK, Konar SK, Missios S, Guthikonda B. Relevance of Simpson grading system and recurrence-free survival after surgery for World Health Organization Grade I meningioma. J Neurosurg 2017;126(01):201-211

14 Oyama H, Kito A, Maki H, Hattori K, Noda T, Wada K. Surgical results of parasagittal and falx meningioma. Nagoya J Med Sci 2012;74(1-2):211-216

15 Roberti F, Sekhar LN, Kalavakonda C, Wright DC. Posterior fossa meningiomas: surgical experience in 161 cases. Surg Neurol 2001;56(01):8-20, discussion 20-21

16 Schick U, Hassler W. Surgical management of tuberculum sellae meningiomas: involvement of the optic canal and visual outcome. J Neurol Neurosurg Psychiatry 2005;76(07):977-983

17 Sekhar LN, Swamy NK, Jaiswal V, Rubinstein E, Hirsch WE Jr, Wright DC. Surgical excision of meningiomas involving the clivus: preoperative and intraoperative features as predictors of postoperative functional deterioration. J Neurosurg 1994;81(06): 860-868

18 Sekhar LN, Wright DC, Richardson R, Monacci W. Petroclival and foramen magnum meningiomas: surgical approaches and pitfalls. J Neurooncol 1996;29(03):249-259

19 Talacchi A, Biroli A, Soda C, Masotto B, Bricolo A. Surgical management of ventral and ventrolateral foramen magnum meningiomas: report on a 64-case series and review of the literature. Neurosurg Rev 2012;35(03):359-367, discussion 367-368

20 Wirsching HG, Morel C, Gmür C, et al. Predicting outcome of epilepsy after meningioma resection. Neuro-oncol 2016;18(07): 1002-1010

21 Kuratsu J, Kochi M, Ushio Y. Incidence and clinical features of asymptomatic meningiomas. J Neurosurg 2000;92(05):766-770

22 Otero-Rodriguez A, Tabernero MD, Munoz-Martin MC, et al. Reevaluating Simpson grade I, II, and III resections in neurosurgical treatment of World Health Organization grade I meningiomas. World Neurosurg 2016;96:483-488

23 Nanda A, Javalkar V, Banerjee AD. Petroclival meningiomas: study on outcomes, complications and recurrence rates. J Neurosurg 2011;114(05):1268-1277
24 Clark VE, Erson-Omay EZ, Serin A, et al. Genomic analysis of nonNF2 meningiomas reveals mutations in TRAF7, KLF4, AKT1, and SMO. Science 2013;339(6123):1077-1080

25 Gousias K, Schramm J, Simon M. The Simpson grading revisited: aggressive surgery and its place in modern meningioma management. J Neurosurg 2016;125(03):551-560

26 Chaichana KL, Gadkaree S, Rao K, et al. Patients undergoing surgery of intracranial metastases have different outcomes based on their primary pathology. Neurol Res 2013;35(10):1059-1069

27 Chan RC, Thompson GB. Morbidity, mortality, and quality of life following surgery for intracranial meningiomas. A retrospective study in 257 cases. J Neurosurg 1984;60(01):52-60

28 Minniti G, Amichetti M, Enrici RM. Radiotherapy and radiosurgery for benign skull base meningiomas. Radiat Oncol 2009;4:42

29 Chaichana KL, Pendleton C, Jackson C, et al. Deep venous thrombosis and pulmonary embolisms in adult patients undergoing craniotomy for brain tumors. Neurol Res 2013;35(02):206-211

30 Constantini S, Kornowski R, Pomeranz S, Rappaport ZH. Thromboembolic phenomena in neurosurgical patients operated upon for primary and metastatic brain tumors. Acta Neurochir (Wien) 1991;109(3-4):93-97

31 Cosetti MK, Tawfik K, Fouladvand M, Roland JT Jr, Lalwani AK. Diplopia due to skew deviation following neurotologic procedures. Otol Neurotol 2012;33(05):840-842

32 Zheng Z, Chen P, Fu W, et al. Early and late postoperative seizure outcome in 97 patients with supratentorial meningioma and preoperative seizures: a retrospective study. J Neurooncol 2013;114(01):101-109

33 Chaichana KL, Parker SL, Olivi A, Quiñones-Hinojosa A. Long-term seizure outcomes in adult patients undergoing primary resection of malignant brain astrocytomas. Clinical article. J Neurosurg 2009;111(02):282-292

34 Chaichana KL, Pendleton C, Zaidi H, et al. Seizure control for patients undergoing meningioma surgery. World Neurosurg 2013;79(3-4):515-524

35 Wu A, Weingart JD, Gallia GL, et al. Risk factors for preoperative seizures and loss of seizure control in patients undergoing surgery for metastatic brain tumors. World Neurosurg 2017;104:120-128

36 Englot DJ, Chang EF, Vecht CJ. Epilepsy and brain tumors. Handb Clin Neurol 2016;134:267-285

37 Dijkstra M, van Nieuwenhuizen D, Stalpers LJ, et al. Late neurocognitive sequelae in patients with WHO grade I meningioma. J Neurol Neurosurg Psychiatry 2009;80(08):910-915

38 Bruggemans EF. Cognitive dysfunction after cardiac surgery: pathophysiological mechanisms and preventive strategies. Neth Heart J 2013;21(02):70-73 